\title{
Salinity Variations over Zhejiang Province Waters, China
}

\author{
Xiaohui Zhao, Feng Gui, Venkata Subrahmanyam Mantravadi*, Liuzhu Wang \\ Zhejiang Ocean University Marine Science and Technology College, Zhoushan, China \\ Email: *mamvensu@gmail.com
}

How to cite this paper: Zhao, X.H., Gui, F., Mantravadi, V.S. and Wang, L.Z. (2018) Salinity Variations over Zhejiang Province Waters, China. Open Access Library Journal, 5: e4562.

https://doi.org/10.4236/oalib.1104562

Received: April 2, 2018

Accepted: May 4, 2018

Published: May 7, 2018

Copyright $\odot 2018$ by authors and Open Access Library Inc.

This work is licensed under the Creative Commons Attribution International License (CC BY 4.0).

http://creativecommons.org/licenses/by/4.0/

\section{(c) (7) Open Access}

\begin{abstract}
In this article, we analyzed the monthly, seasonal and annual salinity variations and their relations with sea surface temperature (SST), rainfall over the Zhejiang province from 2005 to 2017. SST and rainfall were chosen as the main influence factors. There is an inverse relationship between rainfall and salinity. And the SST has a positive relation with salinity, showing slightly seasonal difference. The vertical variation is checked from surface to 150 meter depth, and $50 \mathrm{~m}$ is suggested to be a separating layer for salinity variations. We found that monthly changes in salinity are more variable in seawater at different depths. Seasonal changes in salinity in this area are significant. In winter and spring, the temperature is low, evaporation is small, and there is little rainfall, resulting in relatively higher salinity; frequent typhoon in summer and autumn with a large amount of freshwater input from the Yangtze River causes a lower salinity. For annual changes, we found an increasing trend over the surface as well as in sub-surface. In addition, we found initially that the stratification of the saline waters in Zhejiang Province makes the sub-surface salinity higher.
\end{abstract}

\section{Subject Areas}

Environmental Sciences, Oceanology

\section{Keywords}

Salinity, Sea Surface Temperature, Rainfall, Seasonal and Annual Variations

\section{Introduction}

Salinity is one of the main parameters used in oceanographic studies. The average salinity of the ocean water is about $35 \%$. However, there are regional variations in the salinity. For global climate variability, ocean salinity is an essential 
variable playing an important role [1]. Besides horizontal variations there are vertical variations as well in the distribution of salinity in the oceans. Distribution of salinity in the world oceans and its interannual variability is having important role in climatic studies and water mass formation [2]. The variations in salinity are the result of certain physical processes such as evaporation, precipitation and freezing. Salinity is highly related to local evaporation (E) and precipitation $(\mathrm{P})$ in the global ocean and in the coastal region to river discharges. Earlier studies reveal the impact of precipitation/freshwater flux on the ocean stratification and pointed out that the salinity stratification strongly affected the ocean dynamics and air-sea interaction [3]. So far, ocean salinity studies were mainly based on in situ observations, either from traditional conductivity, temperature, and depth (CTD) profiles or newly employed Array for Real-Time Geotropic Oceanography (Argo) floats, and the ocean models.

As for the availability of more salinity observations from Argo floats [4], it is becoming more and more important to develop methods to assimilate salinity profile data into ocean circulation models. Salinity has an impact on the density field and on ocean currents and water transports [5] [6] [7] [8]. Salinity is also important in certain places, where it controls the stability of the water column and hence to a degree, mixing and air-sea interaction. Temperature and salinity data have also been compared to identify climatic changes on decadal time scales [9] [10] [11] [12] [13] and discuss the global salinity changes as providing the dominant signal of climate change in the oceans over the past few decades.

Salinity decreases in case fresh water is added to the ocean water. The process of evaporation is certainly the most important factor that controls the distribution of the surface salinity. Evaporation is controlled by temperature, relative humidity and the instability or stability in the lower layers of the atmosphere. Thus it is clear that the conditions which favor the higher rate of evaporation will naturally produce areas of high surface salinity. Northwestern pacific is prone to have higher number for storm, by which higher rainfall occurred over the ocean and land. Fresh water will be added to ocean surface as rainfall and river discharges tends to dilute the sea water and decrease salinity. The influx of fresh water by river is another important factor which brings down the degree of salinity in ocean water. In the Zhejiang province, China Changjiang River or Yangtze River is the main source for fresh water input to the East China Sea [14].

The aim of this paper is to find out the variations on monthly, seasonal and annual basis and the relations with SST, rainfall over the Zhejiang province. Due to lack of river discharge data, the relation with salinity has not been given, however previous studies on the variation of salinity due to river discharge have been quoted.

\section{Data and Methods}

Study area: Zhejiang province is one of the typical areas over East China coast, consisting of coastal area as well as islands. Zhejiang coastal waters are influ- 
enced by the rivers and also by rainfall due to typhoons. The typical area of Zhejiang province is shown in Figure 1.

Data: Argo salinity profiles and gridded monthly Argo product on $1^{\circ}$ grids has been used for this study to find out the variations over Zhejiang waters during the period from 2005 to 2017. The Argo T/S profiles are available at the Global Ocean Data Assimilation Experiment (GODAE), and the monthly Argo product is provided by the Scripps Institution of Oceanography [15]. In addition, we use precipitation and SST in this study to find the relation between those. The Global Precipitation Climatology Project (GPCP) version 2.3 monthly data on $2.5^{\circ}$ grids are available at NASA GSFC [16] [17]. The NOAA version 2 Optimum Interpolation Sea Surface Temperature (OISST) data on $1^{\circ}$ grids are obtained from the Physical Sciences Division (PSD) of the Earth System Research Laboratory (ESRL) [18]. Further statistical analysis has been done to find out the relation between salinity with SST and Rainfall. T-test has been done to check the data and correlation coefficients are calculated with $95 \%$ confidence level.

\section{Results}

\section{Variation of salinity:}

Mean monthly composite salinity profiles variations from surface to $-150 \mathrm{~m}$ are given in Figure 2 over the period 2005 to2017. The black dotted line is the composite salinity variation. Figure 2 clearly indicating that there is a monthly variation, with minimum surface salinity (34.38 psu) in July and higher salinity (34.81 psu) in March. However, salinity at $150 \mathrm{~m}$ depth reveals a lower salinity (34.8 psu) in January and higher value in September (34.83). During June to October, salinity above $100 \mathrm{~m}$ is increasing with the depth. This is due to higher rainfall occurred during those months which reduce the upper level salinity, however below $100 \mathrm{~m}$ the salinity increase and revealing the natural variation.

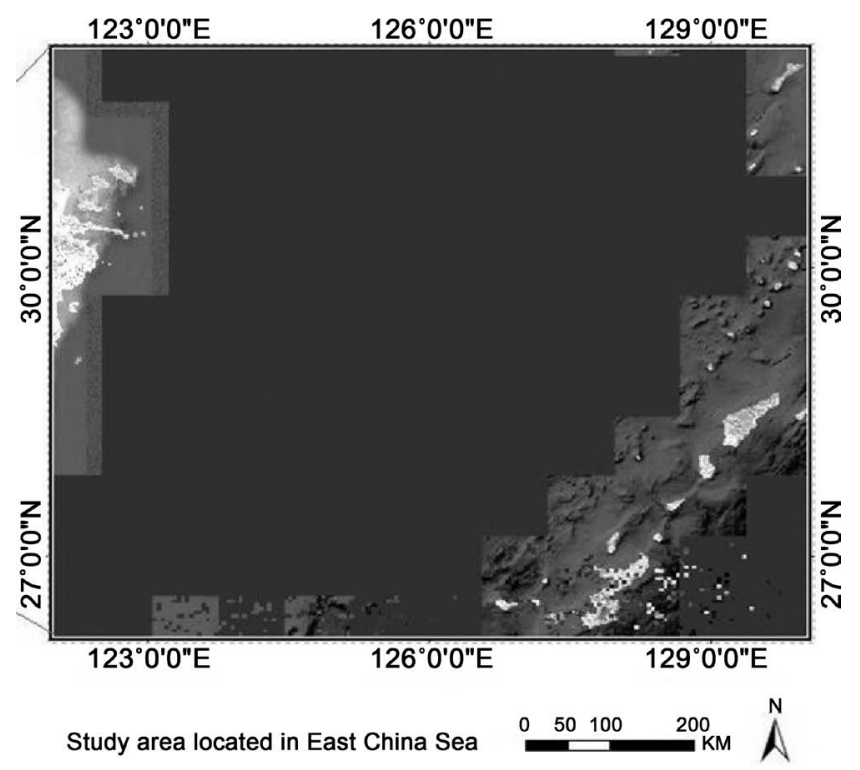

Figure 1. Study area (Zhejiang Waters) is located in East China Sea. 


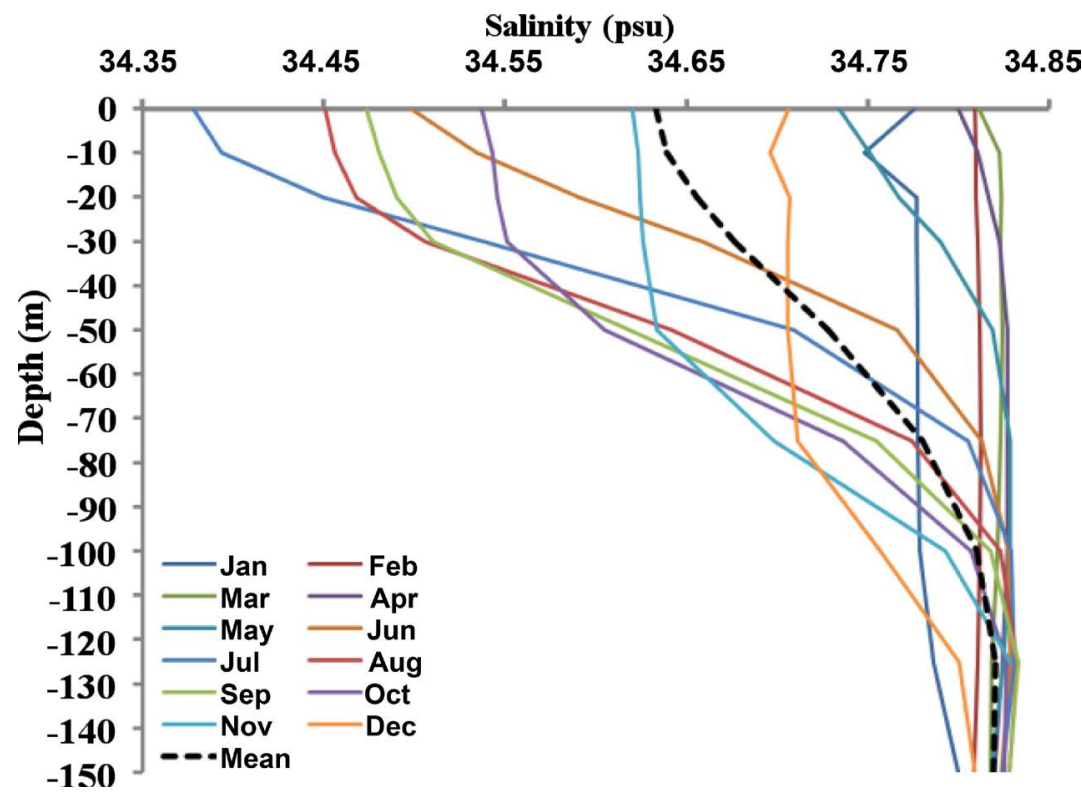

Figure 2. Mean monthly composite salinity profiles during 2005 to 2017 from surface to $150 \mathrm{~m}$ depth. The dotted line is the salinity profile of mean of all the months during the study period.

One can find the February month composite of salinity having similar salinity from surface to $150 \mathrm{~m}$, however in other months there are variations in salinity due to different factors (which will be discussed in later section).

Since there are variations in monthly basis, we checked the seasonal variations also. Figure 3 depicts the variation of salinity at different seasons. Salinity profiles are indicating a significant seasonal variation. In winter and spring salinity are higher than summer and autumn. Higher salinity is mainly due to freezing or lower temperatures over the region. As it is well known that if the water is attains its lower temperatures, salinity increases. This phenomenon can be seen in the Zhejiang waters during winter and spring. However in summer and autumn, Zhejiang waters will experience rainfall due to typhoons. As it is well known that frequency of typhoons are higher over Western Pacific than anywhere in the world. As typhoons bring heavy rainfall and higher winds, salinity will decreases due to rainfall, however due to higher wind speed there will be upwelling and salinity will increase. The degree of rainfall influence will be higher than the upwelling, we cannot find the increase in salinity in monthly basis. However if we check the variations on daily basis (daily variations are not given and discussed in this paper), during typhoon period, salinity will increase at surface due to typhoons winds provided the intensity of the typhoon should be higher.

Figure 4 reveals the mean annual variation of salinity from surface to $150 \mathrm{~m}$ depth. In the year 2008 revealing the lowest salinity at the surface and highest salinity is observed on 2017. There is an increasing trend from 2014. However there is higher salinity can be seen in the years of 2005 and 2007 than the mean salinity variation from surface to $-150 \mathrm{~m}$ depth. During 2008 , salinity is increasing gradually attains mean of the study period by $150 \mathrm{~m}$ depth. The salinity 


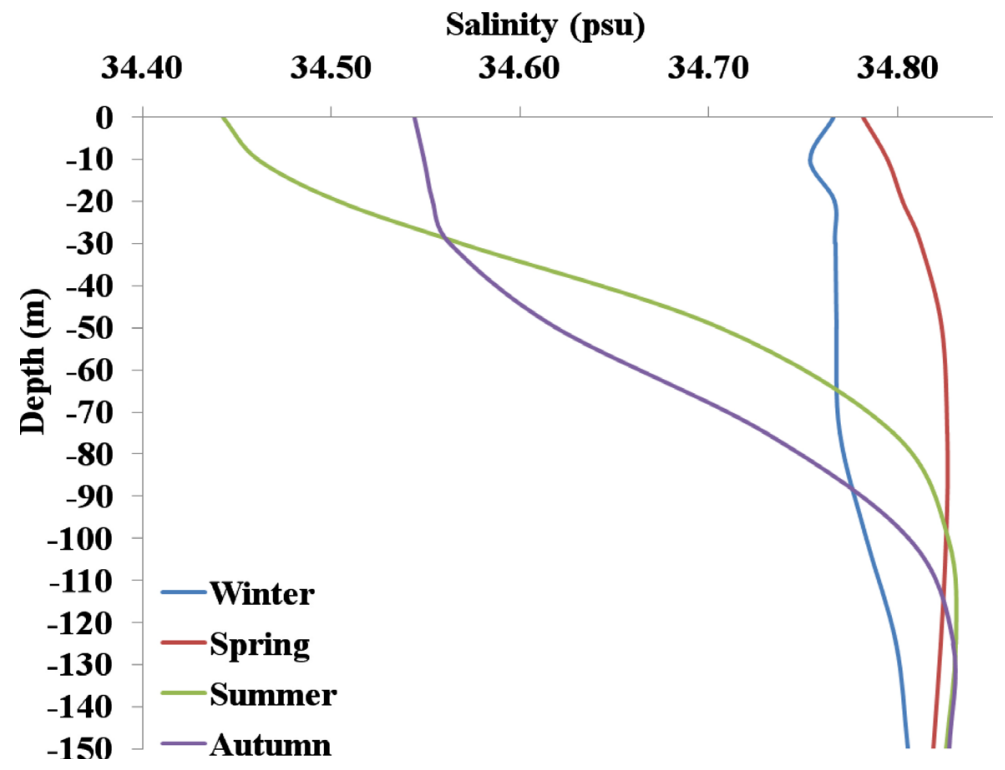

Figure 3. Mean Seasonal salinity variation over Zhejiang waters during 2005-2017 from surface to $150 \mathrm{~m}$ depth.

Salinity (psu)

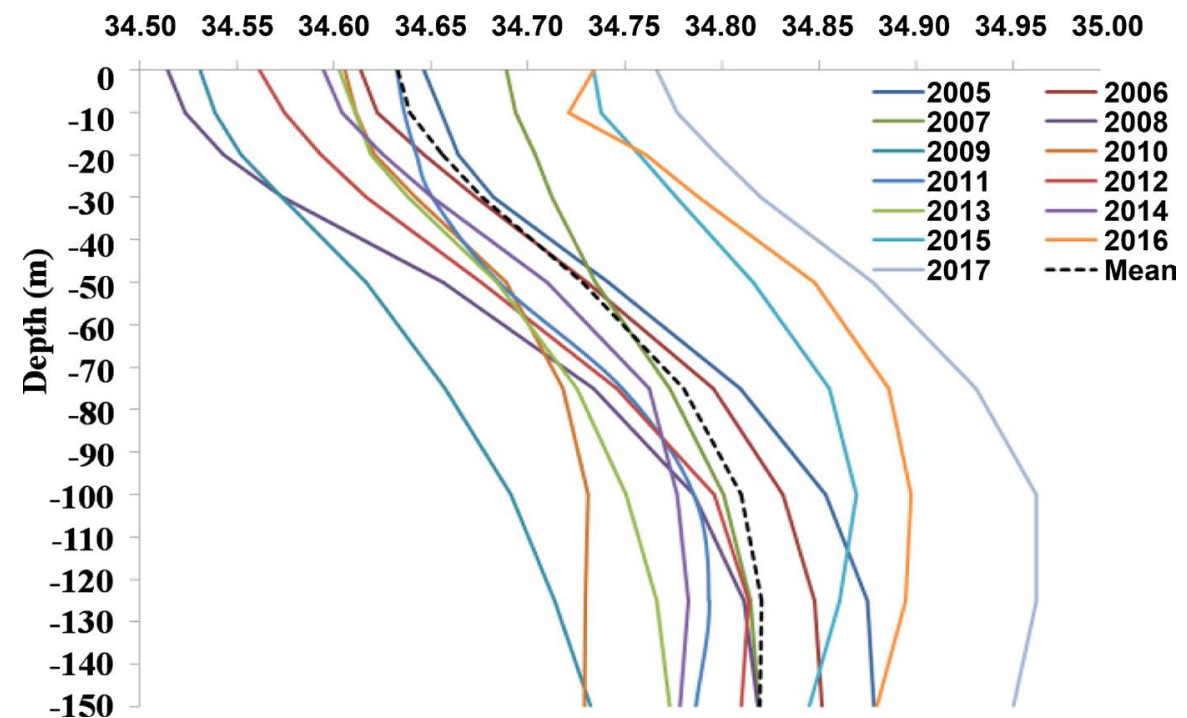

Figure 4. Variation annual salinity in different years over Zhejiang waters during 2005-2017 from surface to $150 \mathrm{~m}$ depth.

above $50 \mathrm{~m}$, salinity variations are similar and increasing in the mixed layer of the ocean. Salinity below $50 \mathrm{~m}$ is indicating there is an increase in salinity to attain its maximum by $150 \mathrm{~m}$ in all years. However, the variations are different in different years. It can be mentioned that the $50 \mathrm{~m}$ layer will be the separating depth for salinity variations. The year 2016 is indicating a peculiar pattern of salinity profile at the surface layers, there is an inversion of salinity can be observed. This may be due to the higher freshwater influx, which reduce the salinity. When we check the monthly variation, January month is peculiar from other months, there is an inversion in the salinity. Winter seasonal variation is also revealing 
the same pattern, which is influencing the annual inversion of salinity.

The variations in the study area over depth of $150 \mathrm{~m}$ have been given in Figure 5. One can see that the salinity is decreasing up to 2009 after that there is an increasing in salinity, however the salinity over surface layers are increasing rapidly from 2014. During 2008-2010, prominent lower salinity patches (34.7 psu) can be observed over $50 \mathrm{~m}$ as well as in $100 \mathrm{~m}$. The reason for these low salinity patches may be due to higher rainfall in those years and the sea is not stratified, however low saline water mass intrusion happened. Since after 2010, there is an inversion pattern observed in salinity, however it is not been seen in individual monthly variation. From the year 2015, salinity is attaining the higher salinity below $25 \mathrm{~m}$. In 2016 and 2017, there are higher saline waters can be seen at the depths of $20-40 \mathrm{~m}$ and $50-60 \mathrm{~m}$, which is prominent.

\section{Factors effecting the variation of salinity:}

Salinity variations occur due to ocean and atmospheric impacts such as SST, upwelling, rainfall/freshwater flux, evaporation, and ice formation. This article gives the effect of mainly SST and rainfall on salinity variations in the flowing sections.

\section{Sea Surface Temperature:}

SST is mainly depends on the solar radiation and is the same for salinity. When SST increased it produce evaporation over the warmer surface. Higher evaporation is leading to increase in salinity. However salinity cannot be increase as SST, but increase in salinity is going to affect the circulation pattern as well as climate. It has been well established that SST in influencing the global climate, however the affect of salinity not been studied in depth. Annual variation of salinity at different depths $(0-150 \mathrm{~m})$ SST and rainfall are given in Figure 6. From Figure 6 clearly indicating that upper surface salinity variations are observed with the SST variations. SST is having higher correlation with of

\section{Year}

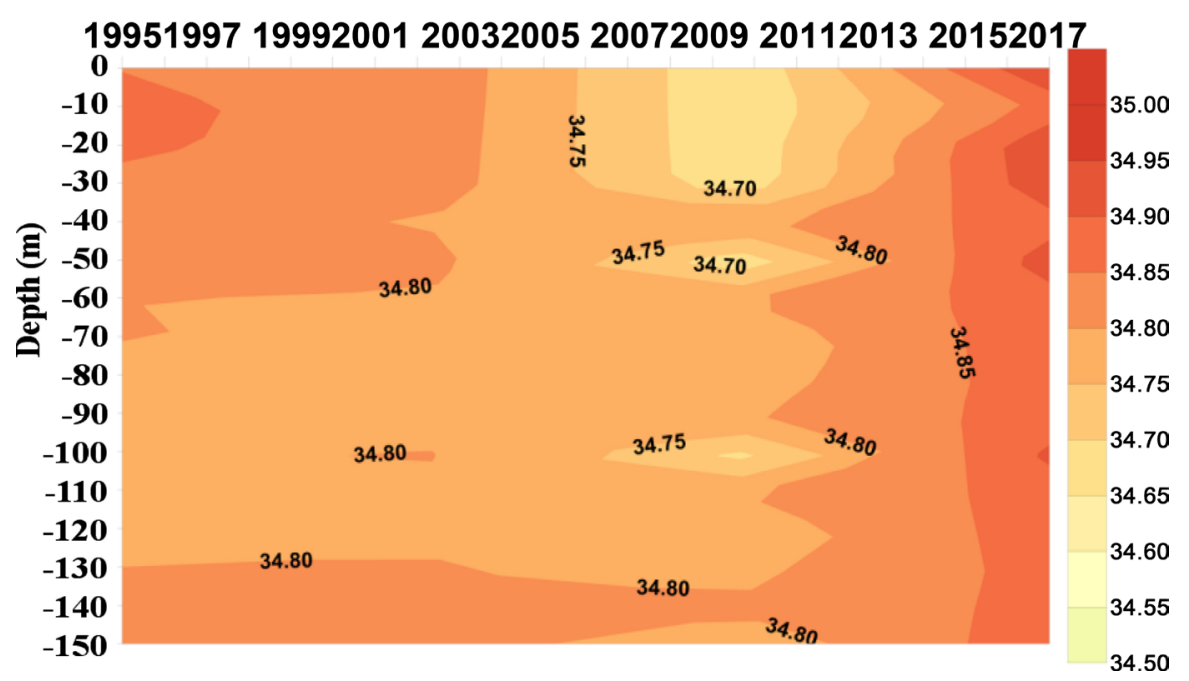

Figure 5. Variation of monthly salinity (psu) with respect to depth $(0-150)$ in different years over Zhejiang waters during 2005-2017. 
50 - $75 \mathrm{~m}$ depth salinity (0.48), however salinity over upper layer above $50 \mathrm{~m}$ revealing lower correlation ( 0.34 with $0 \mathrm{~m}, 0.32$ with $10 \mathrm{~m}, 0.42$ with $20 \mathrm{~m}$ depth) with SST. This relation between SST and salinity reveals when higher SST, salinity increase leading to higher density. The higher density water moves to lower layers, so that stratification of sea water. As it is mentioned in the previous sections, salinity variations are seasonal; the annual variations may be normalizing the variations. Seasonal relation between SST and salinity at different depths are given in Table 1. There is a clear relation during winter and autumn, which are indicating higher correlation. In the winter season, except at $10 \mathrm{~m}$ depth, the correlation coefficients are more than 0.5 , which clearly indicates that increase in salinity during the winter, as the SST decreases. When there is a cold wind passing through the ocean, the temperatures will decrease and begin to condensation, which leads to increase in salinity. In the spring, SST doesn't have a significant relation with salinity. However, SST and Salinity at different depths the correlation coefficients becoming higher with increase in depth. In the summer season, the air temperatures will be higher which increases SST. However there is no significant relation found in summer. Salinity at the depth of $50 \mathrm{~m}$ has relation with SST. This indicates when higher temperatures increased the salinity, higher density waters are moving down to become stratification of water with respect to density.

\section{Rainfall:}

Figure 6 also reveals the variation of annual rainfall variations along with SST and Salinity at different depths. It is clearly evident that when there is higher rainfall occurred salinity decreased. In the year 2010 higher rainfall occurred and subsequently SST and salinity decreased, however decrease in salinity can be observed at 100 - $150 \mathrm{~m}$. At the upper layers above $50 \mathrm{~m}$, salinity indicating increase, this may be due to increase in annual temperature and other factors

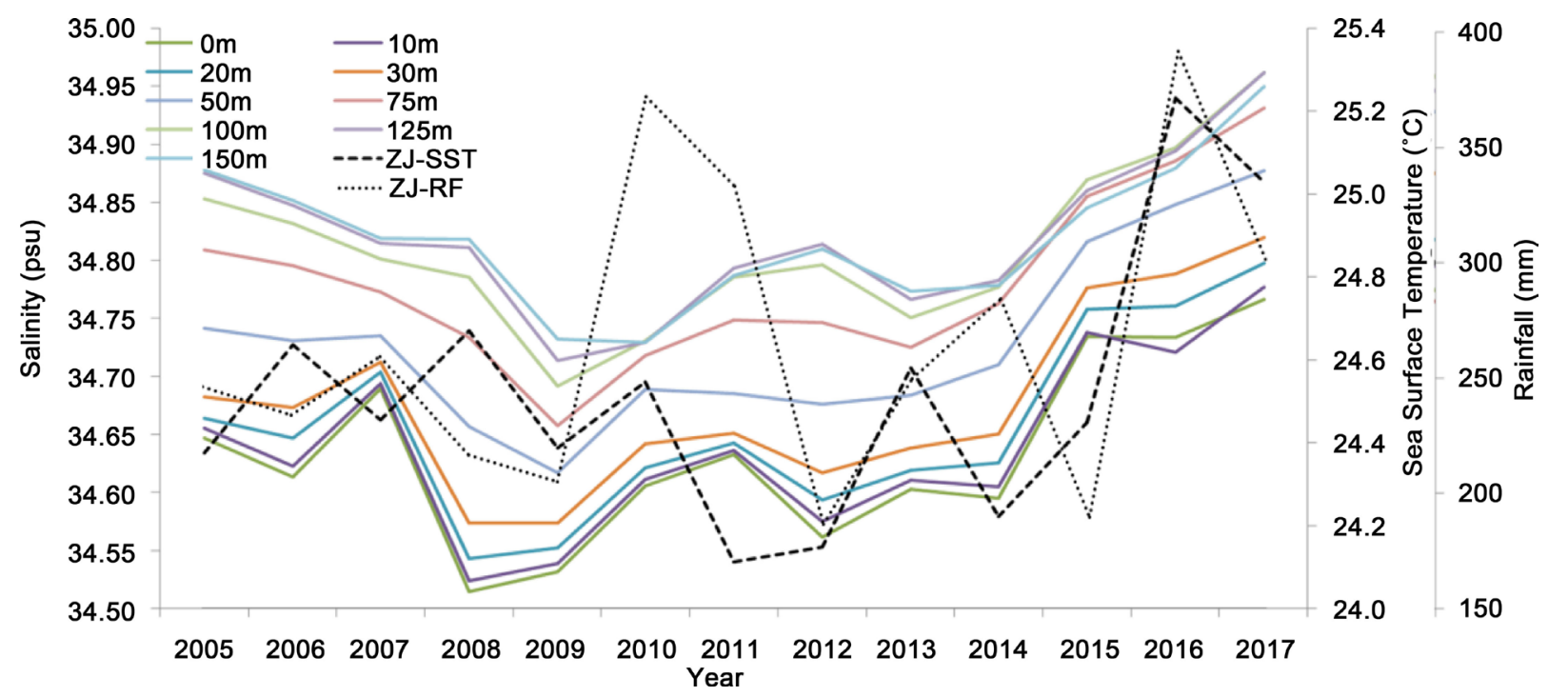

Figure 6. Annual variation of salinity (psu) at different depths (colored lines), Sea surface temperature $\left({ }^{\circ} \mathrm{C}\right.$, dotted lines) and rainfall ( $\mathrm{mm}$, dots) during the study period. Right side axis indicates SST and rainfall. 
influencing such as increase in evaporation, solar radiation etc. the years 2009, 2012 and 2015 are El Nino years, it is clearly evident that the rainfall is lower during those years. The effect of higher SST can be seen on the subsequent year's increase in salinity. This clearly shows that rainfall is effecting the salinity at the time of it occurred, however SST is effecting on the subsequent year salinity. Rainfall is occurring over Zhejiang waters especially due to typhoons and by local convection that influence the salinity immediately. When compare the seasonal variations, the relation between rainfall and salinity at different depths is given in Table 1 . In the winter the relation between the rainfall and salinity are indicating a positive relation. This can inferred as during the winter, there will be precipitation, which can be happened as snow, and the temperatures are less, which leading to increase in salinity. However in spring time rainfall and salinity indicating negative relation. When the temperatures are increasing the snow which occurred during the winter will be melt as fresh water, leading to lower the salinity. During the spring, the negative relation increased from the surface to $150 \mathrm{~m}$. In summer, the rainfall will be less and higher temperatures prevail, the salinity and rainfall have a positive relation. However in the autumn, there will be rainfall due to several typhoons and the river discharge/terrestrial runoff will be higher, which reduces the salinity. That can be observed in the salinity is having negative relation with rainfall, however the magnitude less. Here we have only find the relation with the rainfall, the river discharge or terrestrial runoff not be considered due to lack of data, so we cannot able to include.

\section{Discussion}

Salinity is important for marine science, variations in salinity can affect the physical and biological processes such as climate changes, ocean currents variations, water mass formation also in increasing salinity may have potential threaten to

Table 1. Correlation coefficients (with $95 \%$ confidence level) between Salinity and SST/Rainfall.

\begin{tabular}{cccccccccc}
\hline & \multicolumn{7}{c}{ Salinity } \\
\cline { 2 - 9 } & $0 \mathrm{~m}$ & $10 \mathrm{~m}$ & $20 \mathrm{~m}$ & $30 \mathrm{~m}$ & $50 \mathrm{~m}$ & $75 \mathrm{~m}$ & $100 \mathrm{~m}$ & $125 \mathrm{~m}$ & $150 \mathrm{~m}$ \\
\hline SST & & & & & & & & & \\
Winter & 0.55 & 0.36 & 0.55 & 0.55 & 0.54 & 0.55 & 0.60 & 0.63 & 0.67 \\
Spring & 0.12 & 0.19 & 0.21 & 0.23 & 0.24 & 0.24 & 0.25 & 0.25 & 0.25 \\
Summer & 0.21 & 0.23 & 0.27 & 0.37 & 0.43 & 0.36 & 0.33 & 0.34 & 0.35 \\
Autumn & 0.49 & 0.50 & 0.51 & 0.53 & 0.69 & 0.75 & 0.66 & 0.59 & 0.57 \\
RF & & & & & & & & & \\
Winter & 0.37 & 0.30 & 0.36 & 0.36 & 0.35 & 0.35 & 0.38 & 0.42 & 0.45 \\
Spring & -0.13 & -0.17 & -0.19 & -0.22 & -0.28 & -0.35 & -0.37 & -0.40 & -0.41 \\
Summer & 0.10 & 0.09 & 0.02 & 0.04 & 0.13 & 0.08 & 0.01 & 0.01 & -0.01 \\
Autumn & -0.09 & -0.09 & -0.08 & -0.09 & -0.02 & 0.04 & 0.05 & -0.02 & -0.06 \\
\hline
\end{tabular}


particularly marine animals, and affect the normal functioning of them. From the plots, we can find that seasonal salinity variations have good consistency with local precipitation. Usually spring and winter season have higher salinities, which can be explained by the higher precipitation in summer and autumn. Zhejiang is in east-Asia monsoon area, most precipitation in summer season, known as flooding season (during flooding season, lot of rain and high river discharge). In autumn season, usually have typhoons (in Chinese called autumn typhoon), which can also bring great amount rain, reduces the salinity and the relation between rainfall and salinity have negative relation. In near shore area, surface water salinity is mainly controlled by river discharge. Although many rivers discharge into the East China Sea, $90 \%$ of total river discharge is from the Changjiang River [14] [19] and also have clear seasonal variation [14]. The in situ observational data analysis [20] [21] and numerical experiments [14] [22] have revealed that the summertime distribution of salinity in the East China Sea is significantly affected by the intrusion of the Changjiang fresh water especially in the upper layers.

From Figure 5, we can also find a low surface salinity time between 2008 and 2010. Annual SST is (less than $24.7^{\circ} \mathrm{C}$ ) clearly indicate there is no sufficient temperature for evaporation which does not have influence in variations in salinity. Annual rainfall is lower during 2008 and 2009, however there may be river discharge is higher leading to lower the salinity. The subsurface salinity is indicating a slowly increasing trend; it may be explained as the SST increase and lower rainfall. Also the stratification of saline waters makes sub surface salinity higher. This is the preliminary study on the salinity over the Zhejiang province waters. Further research work has to be done to find the influencing factors for salinity variations in detail. Also to find out how salinity variations are impacting the climate, current system and water mass formation.

\section{Conclusion}

From this study we can conclude that, salinity variations over Zhejiang waters have seasonal variations. Annual variation of salinity is signifying an increasing trend over the surface as well as in sub surface. The depth of $50 \mathrm{~m}$ is dividing the surface and sub surface as a barrier between surface and sub surface waters. SST is having an influence on salinity at surface as well as at subsurface. The relation can be clearly seen in Table 1 . Rainfall affect can be observed on autumn, in autumn season experience higher number of typhoons produces higher rainfall and leading to reduce salinity, there is an inverse relation between rainfall and salinity (Table 1).

\section{Acknowledgements}

This work is supported by the National Key Research and Development Program of China (2017YFA0604902). 


\section{References}

[1] Lagerloef, G. (2002) Introduction to the Special Section: The Role of Surface Salinity on Upper Ocean Dynamics, Air-Sea Interaction and Climate. Journal of Geophysical Research: Oceans, 107, 8000. https://doi.org/10.1029/2002JC001669

[2] Livitus, S. (1986) Annual Cycle of Salinity and Salt Storage in the World Oceans. Journal of Physical Oceanography, 16, 322-343. https://doi.org/10.1175/1520-0485(1986)016<0322:ACOSAS>2.0.CO;2

[3] Masson, S., Boulanger, J.-P., Menkes, C., Delecluse, P. and Yamagata, T. (2004) Impact of Salinity on the 1997 Indian Ocean Dipole Event in a Numerical Experiment. Journal of Geophysical Research: Oceans, 109, C02002. https://doi.org/10.1029/2003JC001807

[4] Roemmich, D., et al. (2001) Argo: The Global Array of Profiling Floats. In: Koblinsky, C.J. and Smith, N.R., Eds., Observing the Oceans in the 21 st Century, Bureau of Meteorology, 248-257.

[5] Cooper, N.S. (1988) The Effect of Salinity in Tropical Ocean Models. Journal of Physical Oceanography, 18, 1333-1347. https://doi.org/10.1175/1520-0485(1988)018<0697:TEOSOT>2.0.CO;2

[6] Roemmich, D., Morris, M., Young, W.R. and Donguy, J.R. (1994) Fresh Equatorial Jets. Journal of Physical Oceanography, 24, 540-558. https://doi.org/10.1175/1520-0485(1994)024<0540:FEJ>2.0.CO;2

[7] Vialard, J. and Delecluse, P. (1998) An OGCM Study for the TOGA Decade. Part I: Role of the Salinity in the Physics of the Western Pacific Fresh Pool. Journal of Physical Oceanography, 28, 1071-1088. https://doi.org/10.1175/1520-0485(1998)028<1071:AOSFTT>2.0.CO;2

[8] Vialard, J. and Delecluse, P. (1998) An OGCM Study for the TOGA Decade. Part II: Barrier Layer Formation and Variability. Journal of Physical Oceanography, 28, 1089-1106. https://doi.org/10.1175/1520-0485(1998)028<1089:AOSFTT>2.0.CO;2

[9] Bindoff, N.L. and McDougall, T.J. (1994) Diagnosing Climate Change and Ocean Ventilation Using Hydrographic Data. Journal of Physical Oceanography, 24, 1137-1152. https://doi.org/10.1175/1520-0485(1994)024<1137:DCCAOV>2.0.CO;2

[10] Wong, A.P.S., Bindoff, N.L. and Church, J.C. (1999) Large Scale Freshening of Intermediate Waters in the Pacific and Indian Oceans. Nature, 400, 440-443. https://doi.org/10.1038/22733

[11] Bryden, H.L., McDonagh, E.L. and King, B.A. (2003) Changes in Ocean Water Mass Properties: Oscillations or Trends? Science, 300, 2086-2088. https://doi.org/10.1126/science.1083980

[12] Dickson, B., Curry, R. and Yashayaev, I. (2003) Recent Changes in the North Atlantic. Philosophical Transactions of the Royal Society A: Mathematical, Physical and Engineering Sciences, 361, 1917-1934. https://doi.org/10.1098/rsta.2003.1237

[13] Curry, R., Dickson, B. and Yashayaev, I. (2003) Ocean Evidence of a Change in the Freshwater Balance of the Atlantic over the Past Four Decades. Nature, 426, 826-829. https://doi.org/10.1038/nature02206

[14] Chang, P.-H. and Isobe, A. (2003) A Numerical Study on the Changjiang Diluted Water in the Yellow and East China Seas. Journal of Geophysical Research, 108, 3299. https://doi.org/10.1029/2002JC001749

[15] Roemmich, D. and Gilson, J. (2009) The 2004-2008 Mean and Annual Cycle of Temperature, Salinity, and Steric Height in the Global Ocean from the Argo Program. Progress in Oceanography, 82, 81-100. 
https://doi.org/10.1016/j.pocean.2009.03.004

[16] Adler, R.F., et al. (2003) The Version 2.1 Global Precipitation Climatology Project (GPCP) Monthly Precipitation Analysis (1979 Present). Journal of Hydrometeorology, 4, 1147-1167. https://doi.org/10.1175/1525-7541(2003)004<1147:TVGPCP>2.0.CO;2

[17] Huffman, G.J., Adler, R.F., Bolvin, D.T. and Gu, G. (2009) Improving the Global Precipitation Record: GPCP Version 2.1. Geophysical Research Letters, 36, L17808. https://doi.org/10.1029/2009GL040000

[18] Reynolds, R.W., Rayner, N.A., Smith, T.M., Stokes, D.C. and Wang, W. (2002) An Improved in Situ and Satellite SST Analysis for Climate. Journal of Climate, 15, 1609-1625. https://doi.org/10.1175/1520-0442(2002)015<1609:AIISAS >2.0.CO;2

[19] Shen, H., Zhang, C., Xiao, C. and Zhu, J. (1998) Change of the Discharge and Sediment Flux to Estuary in Changjiang River. In: Hong, G.H., Zhang, J. and Park, B.K., Eds., Health of the Yellow Sea, Earth Love Publishing Association, 129-148.

[20] Siswanto, E., Nakata, H., Matsuoka, Y., Tanaka, K., Kiyomoto, Y., Okamura, K., Zhu, J.R. and Ishizaka, J. (2008) The Long-Term Freshening and Nutrient Increases in Summer Surface Water in the Northern East China Sea in Relation to Changiang Discharge Variation. Journal of Geophysical Research, 113, C10030. https://doi.org/10.1029/2008JC004812

[21] Kim, H.-C. and Coauthors (2009) Distribution of Changjiang Diluted Water Detected by Satellite Chlorophyll-a and Its Interannual Variation during 1998-2007. Journal of Oceanography, 65, 129-135. https://doi.org/10.1007/s10872-009-0013-0

[22] Moon, J.H., Pang, I.C. and Yoon, J.H. (2009) Response of the Changjiang Diluted Water around Jeju Island to External Forcings: A Modeling Study of 2002 and 2006. Continental Shelf Research, 29, 1549-1564. https://doi.org/10.1016/j.csr.2009.04.007 